\title{
Altered blood glucose concentration is associated with risk of death among patients with community-acquired Gram-negative rod bacteremia
}

\author{
Galo Peralta*1, M Blanca Sánchez², J Carlos Garrido³, Begoña Ceballos ${ }^{4}$ Fátima Mateos³, Inés De Benito 5 and M \\ Pía Roiz
}

\begin{abstract}
Background: Altered blood glucose concentration is commonly observed in patients with sepsis, even among those without hypoglycemic treatments or history of diabetes mellitus. These alterations in blood glucose are potentially detrimental, although the precise relationship with outcome in patients with bacteremia has not been yet determined.

Methods: A retrospective cohort study design for analyzing patients with Gram negative rod bacteremia was employed, with the main outcome measure being in-hospital mortality. Patients were stratified in quintiles accordingly deviation of the blood glucose concentration from a central value with lowest mortality. Cox proportional-hazards regression model was used for determining the relationship of same day of bacteremia blood glucose and death.

Results: Of 869 patients identified 63 (7.4\%) died. Same day of bacteremia blood glucose concentration had a Ushaped relationship with in-hospital mortality. The lowest mortality (2\%) was detected in the range of blood glucose concentration from 150 to $160 \mathrm{mg} / \mathrm{dL}$. Greater deviation of blood glucose concentration from the central value of this range (155 mg/dL, reference value) was directly associated with higher risk of death ( $p=0.002$, chi for trend). The lowrisk group (quintile 1) had a mortality of 3.3\%, intermediate-risk group (quintiles 2, 3 and 4) a mortality of $7.1 \%$, and the high-risk group (quintile 5) a mortality of $12.05 \%$. In a multivariable Cox regression model, the hazard ratio for death among patients in the intermediate-risk group as compared with that in the low risk group was 2.88 ( $95 \%$ confidence interval, 1.01 to $8.18 ; \mathrm{P}=0.048$ ), and for the high risk group it was 4.26 ( $95 \%$ confidence interval, 1.41 to $12.94 ; \mathrm{P}=0.01$ ).

Conclusions: Same day of bacteremia blood glucose concentration is related with outcome of patients with Gramnegative rod bacteremia. Lowest mortality is detected in patients with blood glucose concentration in an interval of 150-160 mg/dL. Deviations from these values are associated with an increased risk of death.
\end{abstract}

\section{Background}

Community acquired Gram-negative bacillus bacteremia (GNB) is a leading cause of hospitalization, sepsis and mortality [1]. Altered blood glucose concentration is frequently detected in patients with sepsis and has been associated with adverse outcome [2-9]. Variable cut-off values of hospital admission blood glucose concentrations with ranges from 100 to $200 \mathrm{mg} / \mathrm{dL}$ have been pre-

*Correspondence: gpf@mundivia.es

${ }^{1}$ Instituto de Investigación y Formación Marques de Valdecilla (IFIMAV), 5

Planta de la Escuela Universitaria de Enfermería, Avda de Valdecilla s/n, 39008, Santander, Spain

Full list of author information is available at the end of the article viously selected for defining outcome in observational studies with different populations as patients with stroke [10], head injuries [11], severe trauma [12], myocardial infarction [13], community acquired pneumonia [14], or patients admitted in a hospital through an emergency department [15].

Based on the negative effects of hyperglycemia in critically ill patients, detected in observational studies, several clinical trials that have tried to prove the benefits of its prevention with intensive insulin therapy with disappointing results. One of the reasons of these results is the potential effect of tight control of glucose blood concen- 
trations causing hypoglycemia [16-18]. In fact hypoglycemia is also associated with negative effect over prognosis. In this situation there is a debate about the relevance of control blood glucose range in critically ill patients in general and specifically in patients with sepsis $[19,20]$.

As there is limited information about outcome in relation with blood glucose concentrations in patients with sepsis and/or bacteremia, we conducted a hospital-based retrospective cohort study in order to investigate the association between same day of bacteremia blood glucose concentration (SDBGC) and mortality in patients with GNB.

\section{Methods}

\section{Hospital setting and patients}

The Sierrallana Hospital is an adult acute-care center in Torrelavega, a city in the North of Spain, which forms part of a health district of 160000 inhabitants. It is a community teaching hospital with 250 beds that has approximately 8000 admissions and 65000 patient visits to the emergency service annually. It includes most major departments and specialties, except transplantation, burns, thoracic surgery, cardiovascular surgery and neurosurgery units. Blood cultures are performed at the hospital in around 1800 patients per year.

A retrospective cohort study design was employed, with the main outcome measure being in-hospital mortality. Patients with Gram-negative rod bacteremia (GNB) from January 1997 to December 2006 were identified by using the microbiology laboratory database and their charts were reviewed retrospectively with a standardized data collection form. Only the community acquired episodes considered accordingly CDC criteria [21] were included in this study cohort. Only the first episode of bacteremia on each admission was included. One hundred and twenty six nosocomial episodes and 23 episodes with no blood glucose measurement recorded during the same day of the bacteremia were excluded. The following data were collected: age; sex; comorbid conditions; dates of hospital admission and discharge; presence of septic shock at the moment of blood culture extraction; specific antimicrobials administered during hospitalization; dates of start and end of antimicrobial administration; surgical procedures and hospitalization in an intensive care unit. The presence of each of the following comorbid conditions was assessed at the time of bacteremia: hepatic dysfunction, malignancy, diabetes mellitus, renal insufficiency, human immunodeficiency virus infection, neutropenia, corticosteroid use, previous transplantation, use of an immunosuppressive agent in the preceding 30 days. The study was approved by the Institutional Review Board of the hospital (Comité Ético de Investigación Clínica de Cantabria), which waived the need for informed consent due to the retrospective nature of the study.

\section{Definitions}

A localized focus infection was considered to be the source or primary focus of bacteremia. Bacteremia was considered to have been nosocomially acquired if it appeared $48 \mathrm{~h}$ after admission and no evidence of infection was present on admission. The bacteremia was categorized as polymicrobial if additional microorganisms were recovered from the blood cultures. The source of the bacteraemia was determined on the basis of the isolation of the same microorganism from the presumed portal of entry and clinical evaluation. Renal insufficiency was indicated by a creatinine value of $2.0 \mathrm{mg} / \mathrm{dL}$. Neutropenia was defined as an absolute neutrophil count $\leq 500$ cells $/ \mathrm{mm}^{3}$ at the onset of the bacteraemia. Immunosuppression was defined as the presence of neutropenia or HIV infection (with CD4 count $\leq 350$ cells/mm3), or receipt of immunosuppressive agents. Comorbidities were assessed by using the Charlson comorbidity score [22]. Septic shock was defined as proposed by Bone et al [23]. Empirical antimicrobial therapy was judged to be either adequate or inadequate on the basis of the in vitro susceptibility of an isolated organism, and/or the initiation of antibiotic treatment within $24 \mathrm{~h}$ of blood culture extraction. Oxyimino-b-lactams (cefuroxime, cefotaxime, ceftriaxone, ceftazidime and aztreonam) were considered to be inappropriate regardless of the MIC for the treatment of infections caused by ESBL-producing Gram-negative microorganisms. Therapy with urinary antiseptics such as norfloxacin, fosfomycin, pipemidic acid or nalidixic acid was considered inadequate [24].

\section{Blood cultures}

The common practice for blood cultures at our hospital is to obtain $20 \mathrm{~mL}$ of venous blood and to inoculate it in equal parts into one aerobic (BacT/ALERT FA aerobic, bioMérieux Corporation, Durham, North Carolina) and one anaerobic blood culture bottle (BacT/ALERT FN, bioMérieux). Blood drawn is performed by nurses from a peripheral vein three times at intervals of 30 minutes. As a routine practice at our hospital a positive finding of microbial growth in the blood culture is reported to the attending physicians before the results of antimicrobial susceptibility test are known and organism identification is established.

\section{Same day of bacteremia blood glucose measurement}

In patients with more than one blood glucose measurement obtained on the same day of the bacteremia only the first one was considered for the analysis. Blood glucose tests were performed at the clinical chemistry laboratory on venous samples by the glucose oxidase method. 


\section{Statistical analysis}

Bivariable analyses were conducted to determine the association between potential risk factors and mortality. Of primary interest was the association between blood glucose concentration and in hospital mortality. Categorical data were compared by the chi-square or Fisher's exact tests. Quantitative data were compared by Student's $t$ test or the Mann-Whitney $U$ test, as appropriate. To evaluate the effect of different levels of blood glucose concentration on mortality, relative risks and 95 percent confidence intervals were calculated as hazard ratios derived from the Cox proportional-hazards regression model. Multivariable models were fitted with use variables with a $P$ value $<0.1$ in the univariate. The level of significance was set at $\mathrm{P}<0.05$. The SPSS (version 14) software package was used for all analyses.

\section{Results}

\section{Patient population}

During the study period, blood cultures were performed in 18094 patients and were positive in 2678. Among these, 1018 patients were identified as having GNB. After considering inclusion/exclusion criteria, 869 cases were analyzed. The demographic and clinical characteristics of these patients are listed in Table 1. The median age of the patients was 75 years (interquartile range, $64-82$ years). In 721 (83\%) blood cultures were obtained at the emergency department, and in 821 (94.5\%) blood glucose determination was performed in samples obtained in the emergency department. Of the selected patients, 672 (77.3\%) were hospitalized and the remainder were diagnosed of bacteremia after the patients had been discharged from the emergency department and re-evaluated in an outpatient clinic.

The main sites of infection were as follows: urinary in 484 patients (55.7\%), biliary in $157(18.1 \%)$; unknown in 116 (13.3\%); abdominal in 37 (4.3\%); enteric in 28 (3.2\%); pneumonia in $16(1.8 \%)$, skin in $13(1.5 \%)$ and spontaneous bacterial peritonitis in $8(0.9 \%)$.

\section{Blood glucose concentrations}

The range of SDBGC was 52 to $582 \mathrm{mg} / \mathrm{dL}$. The relationship of mortality and blood glucose concentration showed an asymmetric $U$ shape distribution with the lowest mortality among patients with glucose blood concentration of 151-160 mg/dL (Figure 1).

Patients were divided into subgroups according the difference of the blood glucose concentration with the central value of the interval with lowest mortality $(155 \mathrm{mg} /$ $\mathrm{dL}$, reference value). Characteristics of these subgroups (quintiles) are reflected in table 2. The proportion of patients with diabetes mellitus or liver cirrhosis was much higher among those classified in the $5^{\text {th }}$ quintile. A relationship between the absolute difference of blood glu-
Table 1: Demographic and clinical characteristics of patients with bloodstream infections due to Gramnegative bacilli.

\begin{tabular}{|c|c|}
\hline Characteristics & Value \\
\hline \multicolumn{2}{|l|}{ Demographics } \\
\hline Male sex & $458(52.7)$ \\
\hline Age $>65 y$ & $635(73.1)$ \\
\hline \multicolumn{2}{|l|}{ Comorbidity } \\
\hline Diabetes mellitus & $139(16)$ \\
\hline Neoplasm & $81(9.3)$ \\
\hline COPD & $81(9.4)$ \\
\hline Dementia & $71(8.2)$ \\
\hline Liver cirrhosis & $48(5.5)$ \\
\hline Stroke & $51(5.9)$ \\
\hline Immunosuppression & $37(4.3)$ \\
\hline Chronic renal failure & $29(3.4)$ \\
\hline Charlson index $\geq 3$ & 145 (16.7) \\
\hline
\end{tabular}

\section{Microorganism}

\begin{tabular}{lc}
\hline E. coli & $710(81.7)$ \\
\hline Klebsiella spp. & $53(6.1)$ \\
\hline Proteus spp. & $44(5.1)$ \\
\hline Salmonella spp. & $39(4.5)$ \\
\hline Enterobacter spp. & $22(2.5)$ \\
\hline
\end{tabular}

Polymicrobial bacteremia

$67(7.7)$

Adequate empirical treatment

$648(74.6)$

Presentation 


\section{Table 1: Demographic and clinical characteristics of patients with bloodstream infections due to Gram- negative bacilli. (Continued)}

\begin{tabular}{lc}
\hline Septic shock & $9(1.0)$ \\
\hline Outcome & \\
\hline Required ICU & $29(3.3)$ \\
\hline In hospital mortality & $63(7.2)$ \\
\hline
\end{tabular}

Data are no. (\%) of patients. ICU: Intensive care unit.

cose concentration respect the reference value and mortality was detected (Figure 2).

On the basis of the findings presented in figure 2, we combined subgroups into three categories designated as low-risk (quintile 1, corresponding to blood glucose concentration from 140 to $170 \mathrm{mg} / \mathrm{dL}$ ), intermediate-risk (quintiles 2, 3 and 4, corresponding to blood glucose concentration from $93 \mathrm{mg} / \mathrm{dL}$ to $139 \mathrm{mg} / \mathrm{dL}$ and from 171 $\mathrm{mg} / \mathrm{dL}$ to $217 \mathrm{mg} / \mathrm{dL}$ ), and high-risk (quintile 5, corresponding to blood glucose concentration $<93 \mathrm{mg} / \mathrm{dL}$ or greater than $217 \mathrm{mg} / \mathrm{dL}$ ). Mortality in the intermediaterisk category was $7.1 \%$ (95\% Confidence interval: $5 \%$ to 9.3\%), which was similar to the average mortality of $7.4 \%$ for the entire cohort.

\section{Predictors of mortality}

Risk factors for death in a univariate analysis are reflected in table 3. Kaplan-Meier estimates of survival for all subjects according to blood glucose concentration risk categories are shown in figure 3. In a multivariable Cox regression model, the hazard ratio for death among patients in the intermediate-risk group according to

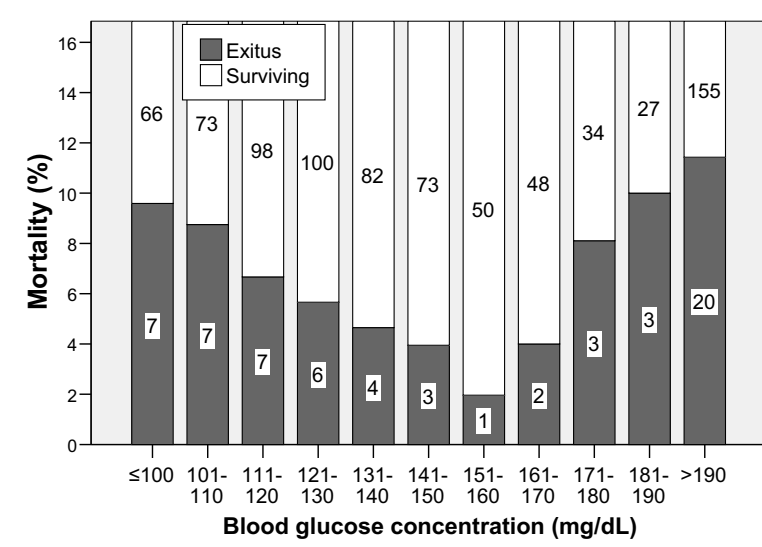

Figure 1 In hospital mortality according to blood glucose concentration. The numbers inside the bars reflect the number of patients in each group. blood glucose concentration as compared with that in the low risk group was 2.88 (95 percent confidence interval, 1.01 to $8.18 ; \mathrm{P}=0.048$ ), and for the high risk group it was 4.26 (95 percent confidence interval, 1.41 to 12.94 ; $\mathrm{P}=$ $0.01)$. Other factors associated with death are reflected in table 4 . When we selected non-diabetic patients for the analysis the hazard ratio for death among patients in the intermediate-risk group according to blood glucose concentration as compared with that in the low risk group was 2.76 (95 percent confidence interval, 0.96 to 7.98 ; $\mathrm{P}=$ 0.06 ), and for the high risk group 5.11 (95 percent confidence interval, 1.55 to $16.92 ; \mathrm{P}=0.008$ ).

\section{Discussion}

In this cohort study of patients with GNB, SDBGC was independently associated with prognosis. SDBGC had a U-shaped relationship with in-hospital mortality with the lowest mortality in patients with SDBGC of $150-160 \mathrm{mg} /$ $\mathrm{dL}$. Based on the deviation of blood glucose concentration from the value with the lowest mortality, we classified patients in groups with low, intermediate, and high risk categories of death. As compared with the low risk blood glucose concentration category, intermediate risk concentration category and high risk category were associated with hazard ratios for death of 2.88 and 4.6, respectively. The increased risk was similar for patients without diabetes mellitus. Although several other studies have made risk assessments for patients with GNB, this is, to our knowledge, the first observational study to evaluate the effect of the deviation from a reference level of blood glucose concentration on outcome in this population.

Hyperglycemia associated with insulin resistance is common in critically ill patients and, although it can be considered an adaptive response, it has been associated with outcome [2,7,16-18]. Several observational studies have demonstrated that elevated initial blood glucose is independently associated with prognostic of severe acute illness [25]. However, the specific consequences of hyperglycemia in patients with sepsis have not quite been addressed $[7,8,19,26]$. Hypoglycemia is also a manifestation of sepsis [2-5] and is associated with a worse outcome in hospitalized patients with acute illnesses $[4,6]$ and specifically in patients with E. coli bacteremia [5].

As the initial altered blood glucose has been considered detrimental in the last years several studies have evaluated the effect of controlling blood glucose concentrations in critically ill patients with insulin therapy over mortality. A prospective randomized non-blind trial showed that critical medical intensive care unit patients had a slight and not significant reduction in ICU mortality of $2.8 \%$ when treated with intensive insulin therapy to achieve target levels of blood glucose concentration from 80 to $100 \mathrm{mg} / \mathrm{dL}$ when compared with patients receiving conventional glucose control (target blood glucose level 
Table 2: Baseline characteristics of patients with GNB according to quintiles of the absolute difference of the SDBGC respect the reference value of lowest mortality $(155 \mathrm{mg} / \mathrm{dL})$.

\begin{tabular}{|c|c|c|c|c|c|c|}
\hline & $\begin{array}{l}1^{\text {st }} \text { Quintile } \\
n=183\end{array}$ & $\begin{array}{l}2^{\text {nd }} \text { Quintile } \\
n=190\end{array}$ & $\begin{array}{l}3^{\text {rd }} \text { Quintile } \\
n=163\end{array}$ & $\begin{array}{l}4^{\text {th }} \text { Quintile } \\
n=167\end{array}$ & $\begin{array}{l}5^{\text {th }} \text { Quintile } \\
n=166\end{array}$ & $\mathbf{p}$ \\
\hline $\begin{array}{l}\text { Range of difference in BGC with the reference value } \\
(\mathrm{mg} / \mathrm{dL})\end{array}$ & $\leq 15$ & $16-29$ & $30-42$ & $43-62$ & $\geq 63$ & - \\
\hline \multicolumn{7}{|l|}{ Demographics } \\
\hline Male sex & 59.0 & 53.7 & 54.0 & 54.5 & 41.6 & 0.02 \\
\hline Age $>65 y$ & 74.9 & 76.3 & 75.5 & 61.4 & 77.1 & 0.006 \\
\hline \multicolumn{7}{|l|}{ Comorbidity } \\
\hline Diabetes mellitus & 10.4 & 11.1 & 6.8 & 4.2 & 49.1 & $<0.001$ \\
\hline Neoplasm & 10.4 & 10.5 & 9.3 & 10.2 & 6.1 & 0.59 \\
\hline COPD & 9.3 & 13.2 & 9.9 & 7.8 & 6.1 & 0.2 \\
\hline Dementia & 6.0 & 6.8 & 8.0 & 7.9 & 12.7 & 0.19 \\
\hline Liver cirrhosis & 4.4 & 3.2 & 6.2 & 4.2 & 10.3 & 0.04 \\
\hline Stroke & 5.5 & 6.3 & 3.1 & 6.6 & 7.9 & 0.44 \\
\hline Immunosuppression & 4.4 & 2.1 & 3.7 & 6.0 & 5.5 & 0.39 \\
\hline Chronic renal failure & 2.7 & 2.1 & 4.3 & 2.4 & 5.5 & 0.37 \\
\hline Charlson $\geq 3$ & 11.5 & 16.1 & 13.8 & 18.5 & 14.8 & 0.57 \\
\hline
\end{tabular}

\section{Origin of infection}

\begin{tabular}{lcccccc}
\hline Urinary & 49.5 & 55.0 & 55.3 & 63.0 & 59.1 & 0.12 \\
\hline Biliary & 20.3 & 21.2 & 22.4 & 13.9 & 12.8 & 0.07 \\
\hline Unknown & 17.6 & 12.2 & 12.4 & 9.1 & 15.9 & 0.16 \\
\hline Intra-abdominal & 4.4 & 3.7 & 4.3 & 4.8 & 4.3 & 3.0 \\
\hline Pneumonia & 1.1 & 1.6 & 1.2 & 2.4 & 0.64 \\
\hline Microorganism & & & & & & \\
\hline E. coli & & & & & & \\
\hline
\end{tabular}


Table 2: Baseline characteristics of patients with GNB according to quintiles of the absolute difference of the SDBGC respect the reference value of lowest mortality $(155 \mathrm{mg} / \mathrm{dL})$. (Continued)

\begin{tabular}{lcccccc}
\hline Klebsiella spp. & 6.0 & 3.7 & 6.7 & 6.6 & 7.8 & 0.56 \\
\hline Proteus spp. & 4.4 & 5.8 & 6.1 & 4.8 & 4.2 & 0.9 \\
\hline Salmonella spp. & 5.5 & 3.7 & 3.7 & 4.2 & 5.4 & 0.86 \\
\hline Enterobacter spp. & 2.2 & 3.7 & 1.2 & 1.2 & 4.2 & 0.25 \\
\hline Adequate empirical treatment & & & & & \\
\hline Polymicrobial bacteremia & 82.6 & 80.3 & 85.8 & 81.8 & 83.7 & 0.7 \\
& & & & & & \\
\hline
\end{tabular}

\section{Presentation}

\begin{tabular}{lcccccc}
\hline Septic shock & 0 & 0.5 & 1.8 & 1.2 & 1.8 & 0.35 \\
\hline Outcome & & & & & & \\
& & & & & & \\
\hline Required ICU & 4.4 & 1.6 & 3.1 & 4.2 & 3.6 & 0.58 \\
\hline Death & 3.3 & 6.3 & 7.4 & 7.8 & 12.0 & 0.03 \\
\hline
\end{tabular}

Data are \% of patients. ICU: Intensive care unit.

180-220 mg/dL) [17]. The study only demonstrated a beneficial effect after the first three days of the intensive insulin therapy [17]. Another multicenter randomized prospective trial of intensive versus conventional glycemic control in severe sepsis was closed prematurely

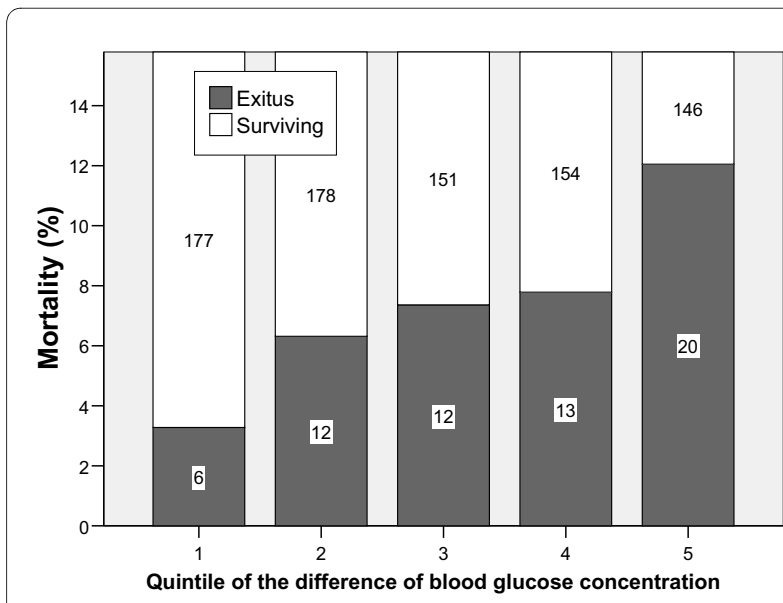

Figure 2 Mortality according to deviation of blood glucose concentration with the reference blood glucose concentration of 155 $\mathrm{mg} / \mathrm{dL}$ which is the central value of the interval with the lowest mortality. Patients are distributed in quintiles of the difference in blood glucose concentration. The numbers inside the bars reflect the number of patients in each group ( $p=0.002$ chi square for linear trend). because of a nearly six fold increase in severe hypoglycemia among the patients in the intensive glycemic control treated group [26]. Moreover, the selection of a strict target blood glucose concentration is not supported by some observational studies, which reveal that optimal blood glucose concentration for these critically ill patients may be higher [25]. On the other hand intensive insulin therapy is potentially detrimental per se $[16,17,27]$. Although hypoglycemia in hospitalized patients is harmful $[4,6,26,27]$, no information is reflected in the literature about the optimal management of hypoglycemia in patients with sepsis, except for causal treatment when feasible.

Our results are consistent with some previous studies. Finney et al [25] found in an observational study that a target blood glucose level of around $145 \mathrm{mg} / \mathrm{dL}$ may be associated with a better outcome in critically ill patients. We have detected similar differences in mortality of $2.7 \%$ than a previous randomized clinical trial, when we compare patients with blood glucose concentration of $80-100$ $\mathrm{mg} / \mathrm{dL}$ and $180-200 \mathrm{mg} / \mathrm{dL}$ that were the end points defined in that trial [17]. However, the optimal blood glucose levels may be different after the first days of hospital admission [17] and our data are referred to the day of the bacteremia. One recent observational study from Australia in critically ill patients has detected also a U shape relationship of blood glucose concentration with mortal- 
Table 3: Univariate analysis of factors associated with mortality in patients with GNB.

\begin{tabular}{|c|c|c|c|c|}
\hline & $\begin{array}{l}\text { Surviving } \\
N=806\end{array}$ & $\begin{array}{l}\text { Death } \\
N=63\end{array}$ & RR $(95 \% \mathrm{Cl})$ & $\mathbf{P}$ \\
\hline \multicolumn{5}{|l|}{ Demographics } \\
\hline Male & $426(52.9)$ & $32(50.8)$ & $0.93(0.58-1.49)$ & 0.43 \\
\hline Age $>65 y$ & $581(72.2)$ & $54(85.7)$ & $2.20(1.11-4.39)$ & 0.01 \\
\hline \multicolumn{5}{|l|}{ Comorbidity } \\
\hline Diabetes mellitus & $130(16.2)$ & $9(14.3)$ & $0.87(0.56-2.41)$ & 0.43 \\
\hline Neoplasm & $74(9.2)$ & $7(11.1)$ & $1.2(0.57-2.57)$ & 0.38 \\
\hline Immunosuppression & $31(3.9)$ & $6(9.5)$ & $2.36(1.08-5.11)$ & 0.046 \\
\hline Liver cirrhosis & $41(5.1)$ & $7(11.1)$ & $2.13(1.02-4.41)$ & 0.052 \\
\hline Chronic renal failure & $45(5.6)$ & $6(9.5)$ & $1.68(0.76-3.71)$ & 0.16 \\
\hline Charlson index $\geq 3$ & $129(16)$ & $21(33.3)$ & $2.4(1.46-3.92)$ & 0.001 \\
\hline \multicolumn{5}{|l|}{ Microorganism } \\
\hline Escherichia coli & $664(82.4)$ & $46(73)$ & $0.61(0.36-1.03)$ & 0.05 \\
\hline Klebsiella spp. & $48(6.0)$ & $5(7.9)$ & $1.33(0.56-3.17)$ & 0.34 \\
\hline Proteus spp. & $40(5.0)$ & $4(6.3)$ & $1.27(0.48-3.34)$ & 0.4 \\
\hline Salmonella spp. & $34(4.2)$ & $5(7.9)$ & $1.84(0.78-4.32)$ & 0.14 \\
\hline Enterobacter spp. & $19(2.4)$ & $3(4.8)$ & $1.93(0.65-5.67)$ & 0.21 \\
\hline Polymicrobial bacteremia & $56(6.9)$ & $11(17.5)$ & $2.56(1.4-4.64)$ & 0.006 \\
\hline Adequate empirical treatment & $610(83.7)$ & $38(70.4)$ & $0.5(0.28-0.86)$ & 0.014 \\
\hline \multicolumn{5}{|l|}{ Origin of infection } \\
\hline Urinary & $466(58.3)$ & $18(29.0)$ & $0.32(0.19-0.54)$ & $<0.0001$ \\
\hline Biliary & $147(18.4)$ & $10(16.1)$ & $0.86(0.45-1.66)$ & 0.4 \\
\hline Unknown & $101(12.6)$ & $15(24.2)$ & $2.05(1.19-3.54)$ & 0.013 \\
\hline Intra-abdominal & $32(4.09$ & $5(8.1)$ & $1.95(0.83-4.58)$ & 0.12 \\
\hline
\end{tabular}


Table 3: Univariate analysis of factors associated with mortality in patients with GNB. (Continued)

\begin{tabular}{|c|c|c|c|c|}
\hline Pneumonia & $10(1.3)$ & $6(9.7)$ & $5.66(2.86-11.18)$ & $<0.001$ \\
\hline \multicolumn{5}{|l|}{ Presentation } \\
\hline Septic Shock & $4(0.5)$ & $5(7.9)$ & $8.24(4.37-15.54)$ & $<0.0001$ \\
\hline
\end{tabular}

Data are no. (\%) of patients. RR: Relative risk

ity, with lowest levels of mortality in patients with blood glucose concentrations among 100-150 mg/dL [28]. Similarly with this study the $U$ shape relationship of blood glucose concentration with mortality that we have detected is asymmetric and there was more increase in mortality in patients with high than with low blood glucose with respect the range with lowest mortality. If sepsis related mortality has a direct relationship with high or low blood glucose concentration, it can be speculated that increasing blood glucose concentration to achieve an optimal target level could be of potential benefit. The threshold to indicate correction of low blood glucose concentration should first be determined [28].

Our study has several limitations. Data are retrospective and the results came from a population with specific characteristics: patients with GNB, a low proportion of immunosuppression, stay in ICU, septic shock or death, so the extrapolation of these results must be made with caution. As has been commented, the measurements of blood glucose concentration were made at the beginning of the illness, so it remains unknown whether the blood glucose concentrations associated with the lowest mor-

Table 4: Results of Cox analyses examining risk factors for mortality associated with bacteraemia due to Gramnegative bacilli.

\begin{tabular}{llc}
\hline Mortality risk factor & HR (95\% Cl) & p value \\
\hline Charlson index $\geq 3$ & $2.04(1.12-3.69)$ & 0.02 \\
\hline Urinary origin & $0.44(0.23-0.82)$ & 0.01 \\
\hline Lung origin & $4.14(1.54-11.08)$ & 0.005 \\
\hline Polymicrobial bacteremia & $2.6(1.28-5.28)$ & 0.008 \\
\hline Adequate empirical treatment & $0.43(0.23-0.79)$ & 0.006 \\
\hline $\begin{array}{l}\text { Shock } \\
\text { low risk) }\end{array}$ & $9.31(3.42-25.38)$ & $<0.001$ \\
\hline
\end{tabular}

HR: hazard ratio tality would be the same after the initial phases of GNB. However as we select initial blood glucose concentration for the analysis, those are not influenced by therapies as insulin, glucose-containing solutions or parenteral nutrition used during hospitalizations.

In summary, our study indicates that low and high blood glucose concentrations are associated with higher mortality of patients with GNR bacteremia regardless of the presence of diabetes mellitus. Studies to determine the precise correlation between blood glucose concentration and mortality with suspected bacteremia are needed.

\section{Conclusions}

Same day of bacteremia blood glucose concentration is related with outcome of patients with Gram-negative rod bacteremia. Lowest mortality is detected in patients with blood glucose concentration in an interval of 150-160

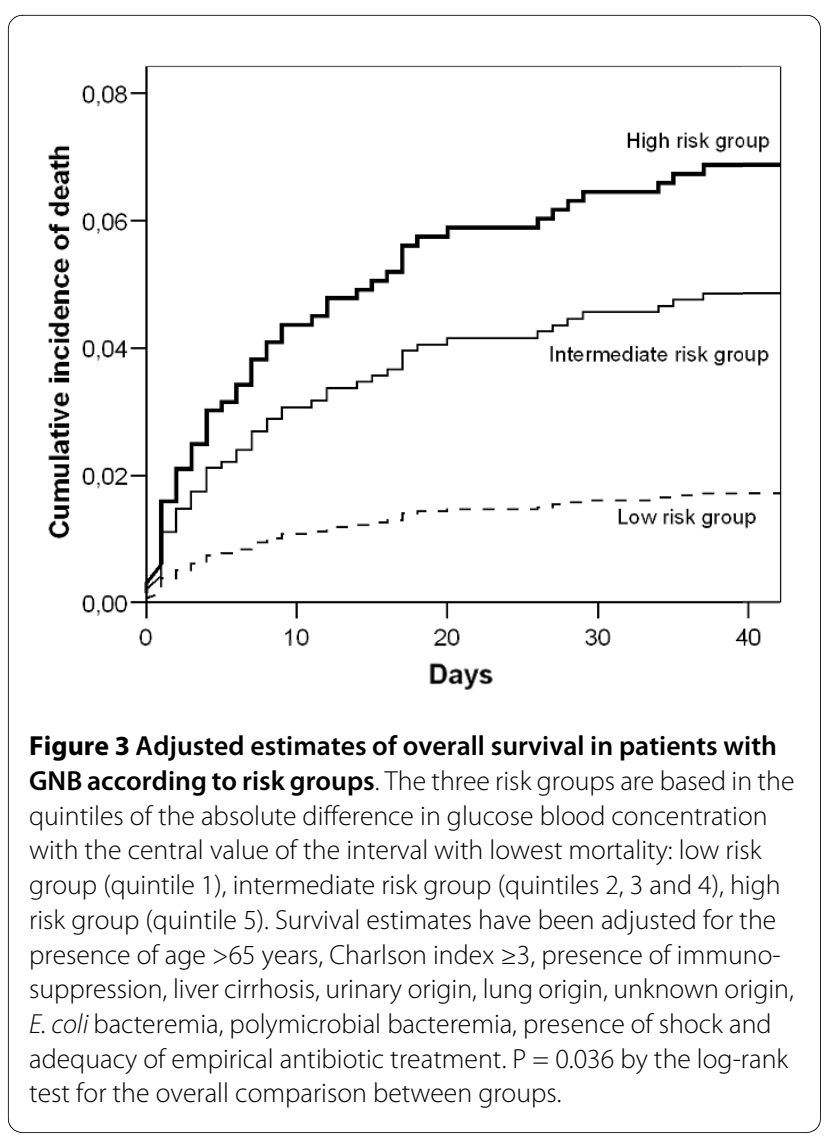


$\mathrm{mg} / \mathrm{dL}$. Deviations from these values are associated with an increased risk of death.

\section{Competing interests}

Galo Peralta has been a consultant in the past for Janssen-Cilag, Wyeth, BristolMyers Squibb, and Boehringer Ingelheim, and has also served as a speaker for Wyeth and GlaxoSmithKline.

\section{Authors' contributions}

GP, MPR, MBS, and JCG were involved in the study conception, BC, FT and IDB were involved in the coordination, and data acquisition, GP performed the data analyses, all authors were involved in the interpretation and validation of the results, GP, MPR and MBS were involved in the drafting of the manuscript and all authors read and approved the final manuscript.

\section{Acknowledgements}

The authors are indebted to all who participated in this study. Thanks to all the health care professionals of the Sierrallana Hospital, and specifically those from the Internal Medicine Service, the Emergency Service, the Microbiology Service and the Biochemistry Service with a special mention to Dra. RodriguezLera.

\section{Author Details}

${ }^{1}$ Instituto de Investigación y Formación Marques de Valdecilla (IFIMAV), 5 Planta de la Escuela Universitaria de Enfermería, Avda de Valdecilla s/n, 39008, Santander, Spain, ${ }^{2}$ Clinical Pharmacology Service, Hospital Universitario "Marqués de Valdecilla", Santander, Spain, 3Biochemistry Service, Hospital Sierrallana, Torrelavega, Spain, ${ }^{4}$ Emergency Service, Hospital Sierrallana, Torrelavega, Spain, 5 Microbiology Service, Hospital Sierrallana, Torrelavega, Spain and ${ }^{6}$ Microbiology Service, Hospital Universitario Marques de Valdecilla, Santander, Spain

Received: 3 November 2009 Accepted: 22 June 2010 Published: 22 June 2010

\section{References}

1. Weinstein MP, Towns ML, Quartey SM, Mirrett S, Reimer LG, Parmigiani G, Reller LB: The clinical significance of positive blood cultures in the 1990s: a prospective comprehensive evaluation of the microbiology, epidemiology, and outcome of bacteremia and fungemia in adults. Clin Infect Dis 1997, 24:584-602.

2. Mizock BA: Alterations in carbohydrate metabolism during stress: $A$ review of the literature. Am J Med 1995, 98:75-84.

3. Miller SI, Wallace RJ Jr, Musher DM, Septimus EJ, Kohl S, Baughn RE: Hypoglycemia as a manifestation of sepsis. Am J Med 1980, 68:649-54.

4. Shilo S, Berezovsky S, Friedlander Y, Sonnenblick M: Hypoglycemia in hospitalized nondiabetic older patients. J Am Geriatr Soc 1998, 46:978-82.

5. Alamgir S, Volkova NB, Peterson MW: Prognostic value of low blood glucose at the presentation of E. coli bacteremia. Am J Med 2006, 119:952-7.

6. Kagansky N, Levy S, Rimon E, Cojocaru L, Fridman A, Ozer Z, Knobler H Hypoglycemia as a predictor of mortality in hospitalized elderly patients. Arch Intern Med 2003, 163:1825-9.

7. Bader MS: Hyperglycemia and mortality in elderly patients with Staphylococcus aureus bacteremia. South Med J 2007, 100:252-6.

8. Frankenfield DC, Omert LA, Badellino MM, Wiles CE, Bagley SM, Goodarzi $\mathrm{S}$, Siegel $\mathrm{JH}$ : Correlation between measured energy expenditure and clinically obtained variables in trauma and sepsis patients. JPEN J Parenter Enteral Nutr 1994, 18:398-403.

9. Krinsley JS: Association between hyperglycemia and increased hospital mortality in a heterogeneous population of critically ill patients. Mayo Clin Proc 2003, 78:1471-8.

10. Capes SE, Hunt D, Malmberg K, Pathak P, Gerstein HC: Stress hyperglycemia and prognosis of stroke in nondiabetic and diabetic patients. Stroke 2001, 32:2426-2436.

11. Jeremitsky E, Omert LA, Dunham CM, Wilberger J, Rodriguez A: The impact of hyperglycemia on patients with severe brain injury. J Trauma 2005, 58:47-50.
12. Laird AM, Miller PR, Kilgo PD, Meredith JW, Chang MC: Relationship of early hyperglycemia to mortality in trauma patients. J Trauma 2004 56:1058-62

13. Hsu CW, Chen HH, Sheu WH, Chu SJ, Shen YS, Wu CP, Chien KL: Initial serum glucose level as a prognostic factor in the first acute myocardial infarction. Ann Emerg Med 2007, 49:618-26.

14. McAlister FA, Majumdar SR, Blitz S, Rowe BH, Romney J, Marrie TJ: The relation between hyperglycemia and outcomes in 2,471 patients admitted to the hospital with community-acquired pneumonia. Diabetes Care 2005, 28:810-5.

15. Cheung NW, Li S, Ma G, Crampton R: The relationship between admission blood glucose levels and hospital mortality. Diabetologia 2008, 51:952-5.

16. Van den Berghe $G$, Wouters $P$, Weekers F, Verwaest $C$, Bruyninckx F, Schetz $M$, Vlasselaers D, Ferdinande $P$, Lauwers $P$, Bouillon R: Intensive insulin therapy in critically ill patients. N Engl J Med 2001, 345:1359-1367.

17. Van den Berghe $G$, Wilmer A, Hermans G, Meersseman W, Wouters PJ, Milants I, Van Wijngaerden E, Bobbaers $\mathrm{H}$, Bouillon R: Intensive insulin therapy in the medical ICU. N Engl J Med 2006, 354:449-61.

18. Vanhorebeek I, Langouche L, Van den Berghe G: Tight blood glucose control with insulin in the ICU: facts and controversies. Chest 2007, 132:268-78.

19. Russell JA: Management of sepsis. NEngl J Med 2006, 355:1699-713.

20. Inzucchi SE: Clinical practice. Management of hyperglycemia in the hospital setting. N Engl J Med 2006, 355:1903-11.

21. Garner JS, Jarvis WR, Emori TG, Horan TC, Hughes JM: CDC definitions for nosocomial infections. Am J Infect Control 1988, 16:128-40.

22. Charlson ME, Pompei P, Ales KL, Mackenzie CR: A new method of classifying prognostic comorbidity in longitudinal populations: development and validation. J Chronic Dis 1987, 40:373-8.

23. Bone RC, Sprung CL, Sibbald WJ: Definitions for sepsis and organ failure. Crit Care Med 1992, 20:724-6.

24. Peralta G, Sanchez MB, Garrido JC, De Benito I, Cano ME, MartinezMartinez L, Roiz MP: Impact of antibiotic resistance and of adequate empirical antibiotic treatment in the prognosis of patients with Escherichia coli bacteraemia. J Antimicrob Chemother 2007, 60:855-63.

25. Finney SJ, Zekveld C, Elia A, Evans TW: Glucose control and mortality in critically ill patients. JAMA 2003, 290:2041-7.

26. Brunkhorst FM, Engel C, Bloos F, Meier-Hellmann A, Ragaller M, Weiler N, Moerer O, Gruendling M, Oppert M, Grond S, Olthoff D, Jaschinski U, John S, Rossaint R, Welte T, Schaefer M, Kern P, Kuhnt E, Kiehntopf M, Hartog C, Natanson C, Loeffler M, Reinhart K, German Competence Network Sepsis (SepNet): Intensive insulin therapy and pentastarch resuscitation in severe sepsis. N Engl J Med 2008, 358:125-39.

27. Krinsley JS: Glycemic control, diabetic status and mortality in a heterogeneous population of critically ill patients before and during the era of tight glycemic control. Semin Thorac Cardiovasc Surg 2006, 18:317-325

28. Bagshaw SM, Egi M, George C, Bellomo R, Australia New Zealand Intensive Care Society Database Management Committee: Early blood glucose control and mortality in critically ill patients in Australia. Crit Care Med 2009, 37:463-70.

Pre-publication history

The pre-publication history for this paper can be accessed here: http://www.biomedcentral.com/1471-2334/10/181/prepub

\section{doi: 10.1186/1471-2334-10-181}

Cite this article as: Peralta et al., Altered blood glucose concentration is associated with risk of death among patients with community-acquired Gram-negative rod bacteremia BMC Infectious Diseases 2010, 10:181 